\title{
Estratégia de Intervenção para Adequação de Sódio e Lipídio em Preparações Alimentares Escolares
}

\author{
Silvia Pereira ${ }^{1}$ Letícia Bottino, ${ }^{2}$ Alexandra Anastacio Monteiro Silva, ${ }^{2}$ \\ Daniele Mendonça Ferreira, ${ }^{2}$ Daniele Silva Bastos Soares, ${ }^{2}$ Patrícia Dias Camacho, ${ }^{2}$ \\ Patrícia Henriques, ${ }^{2}$ Roseane Moreira Sampaio Barbosa ${ }^{2}$
}

\section{RESUMO}

Realizar uma intervenção nutricional por meio da construção e adoção da Ficha Técnica de Preparo com foco na adequação da oferta de sódio e lipídios nas preparações alimentícias. Etapa 1. Diagnóstico: Análise da quantidade de lipídio utilizando a técnica de extração por meio do aparelho de Soxhlet e sódio por pesagem da quantidade de sal de adição utilizado e cálculo da quantidade de sódio utilizando a Tabela Brasileira de Composição de Alimentos e aplicação do roteiro para observação do modo de preparo. Etapa 2. Intervenção: Desenvolvimento e adoção das Fichas Técnicas de Preparação utilizando o modelo recomendado pelo Programa Nacional de Alimentação Escolar. Etapa 3. Avaliação da aceitabilidade pelos escolares segundo o manual do Programa, análise do uso das Fichas Técnicas de Preparo pelo roteiro de observação e da quantidade pelo método já citado. Observou-se um valor de lipídio adequado, com o sódio estando 67,5\% acima do recomendado pelo programa para duas refeições (até 600 miligramas). Após a introdução das Fichas Técnicas de Preparo a quantidade de sódio foi reduzida a 26,4\% da recomendação e a de lipídio manteve-se adequada. A intervenção foi eficaz para promover uma padronização da produção de arroz e feijão por meio da Ficha Técnica de Preparo com adequada quantidade de óleo e sal de adição, promovendo maior qualidade nutricional.

Palavras-chave: Sódio na dieta; lipídeos na dieta; planejamento de cardápio.

\section{INTERVENTION STRATEGY FOR ADEQUATING SODIUM AND LIPID IN SCHOOL FOOD PREPARATIONS}

\section{ABSTRACT}

Carry out a nutritional intervention through the construction and implementation of the Technical Preparation Form focusing on the adequacy of the supply of sodium and lipids in food preparations. Step 1. Diagnosis: Analysis of the amount of lipid using the technique of extraction using the Soxhlet and sodium apparatus by weighing the amount of added salt used and calculating the amount of sodium using the Brazilian Table of Food Composition and application of the script to observe the preparation method. Step 2. Intervention: Development and implementation of the Preparation Technical Sheets using the model recommended by the National School Feeding Program. Step 3. Evaluation of acceptability by students according to the Program manual, analysis of the use of Technical Preparation Sheets by the observation guide and quantity by the method already mentioned above. An adequate lipid value was observed, with sodium, $67.5 \%$ above that recommended by the program for two meals (up to 600 milligrams). After the implementation of the technical preparation sheets, the amount of sodium was reduced to $26.4 \%$ of the recommendation and that of lipid remained adequate. The intervention was effective in promoting a standardization of the production of rice and beans through the Technical Preparation Form with an adequate amount of oil and added salt, promoting greater nutritional quality.

Keywords: Sodium; dietary; dietary fats; menu planning.

\footnotetext{
${ }^{1}$ Autora correspondente. Universidade Federal Fluminense - Faculdade de Nutrição Emília de Jesus Ferreiro. Programa de Pós-Graduação em Ciências da Nutrição. Rua Mário Santos Braga no 30, 40 andar. Niterói/RJ, Brasil. CEP 24020-140. http:// lattes.cnpq.br/9062811018583569. https://orcid.org/0000-0003-1538-4097. spereira@id.uff.br

2 Universidade Federal Fluminense. Faculdade de Nutrição Emília de Jesus Ferreiro. Programa de Pós-Graduação em Ciências da Nutrição. Niterói/RJ, Brasil.
} 


\section{INTRODUÇÃO}

No Brasil, assim como no mundo, observa-se o aumento da ingestão de sódio e lipídios pelas crianças, especialmente relacionados ao elevado consumo de alimentos ultraprocessados e a redução no consumo dos alimentos in natura. ${ }^{1}$ Tendo em vista os malefícios que o excesso desses nutrientes pode causar à saúde, como hipertensão arterial sistêmica e hipercolesterolemia, políticas e programas públicos vêm sendo formulados e aperfeiçoados com o objetivo de promover hábitos alimentares adequados e saudáveis, com destaque para o Programa Nacional de Alimentação Escolar (PNAE).

O Pnae atende as escolas municipais, estaduais, distritais e entidades filantrópicas e conveniadas com o poder público, tendo por finalidade o fornecimento de refeições adequadas que respeitem a cultura alimentar local, promovam a alimentação adequada e saudável, além de incluir a Educação Alimentar e Nutricional como parte de suas estratégias para a promoção da Segurança Alimentar e Nutricional (SAN) no ambiente escolar, visando a garantia do Direito Humano à Alimentação Adequada (DHAA) para os escolares. ${ }^{2}$ As ações relacionadas à alimentação escolar devem ser desenvolvidas pelo nutricionista qualificado e responsável técnico (RT), conforme estabelece a legislação. ${ }^{3}$

Uma das atribuições obrigatórias do nutricionista RT do Pnae é o planejamento dos cardápios a partir da Ficha Técnica de Preparo (FTP). Essa ficha é um instrumento que favorece a padronização das refeições produzidas nas Unidades de Alimentação e Nutrição Escolar (Uane), mostrando-se importante para padronização das etapas de pré-preparo, preparo e distribuição das refeições, além de contribuir para o uso racional dos gêneros alimentícios e, consequentemente, adequação às necessidades nutricionais dos escolares recomendadas pelo PNAE. ${ }^{3}$ Outrossim, a FTP permite maior controle de qualidade higiênico-sanitária, determinação do fluxo de operacionalização, controle de custos, maior eficácia para capacitação dos funcionários e identificação dos pontos críticos. ${ }^{4}$ Desta forma, o objetivo deste estudo foi realizar uma intervenção nutricional em uma escola para avaliação da quantidade de sódio e lipídios adicionados às preparações arroz branco e feijão preto, bem como elaborar e adotar as referentes fichas técnicas.

\section{MÉTODO}

Estudo longitudinal, prospectivo, de intervenção, com natureza quantitativa e qualitativa, realizado em uma escola municipal do município de Niterói - Rio de Janeiro, aprovado pelo comitê de ética de pesquisa da Universidade Salgado de Oliveira, sob o número 71087117.1.0000.5243. Escolheu-se essa unidade pelo fato da mesma possuir parceria com a universidade, permitindo o desenvolvimento de outros trabalhos científicos em seu espaço.

Estão matriculados, no Ensino Fundamental primeiro segmento, aproximadamente 600 alunos, entre 5 e 14 anos, sendo que aproximadamente $50 \%$ deles fazem refeições na escola. O cardápio é planejado pela nutricionista responsável técnica da Fundação Municipal de Educação e há a oferta de uma grande refei-

Editora Unijuí - Revista Contexto \& Saúde - ISSN 2176-7114 - v. 21, n. 44, out./dez. 2021 
ção (almoço) e uma pequena refeição (colação/lanche) em cada turno igualmente para todos os alunos independentemente do ano letivo em que esteja.

O percurso metodológico foi composto pelas etapas de diagnóstico, instituição e avaliação, como demonstrado no fluxograma representado pela Figura 1.

Figura 1 - Fluxograma do percurso metodológico

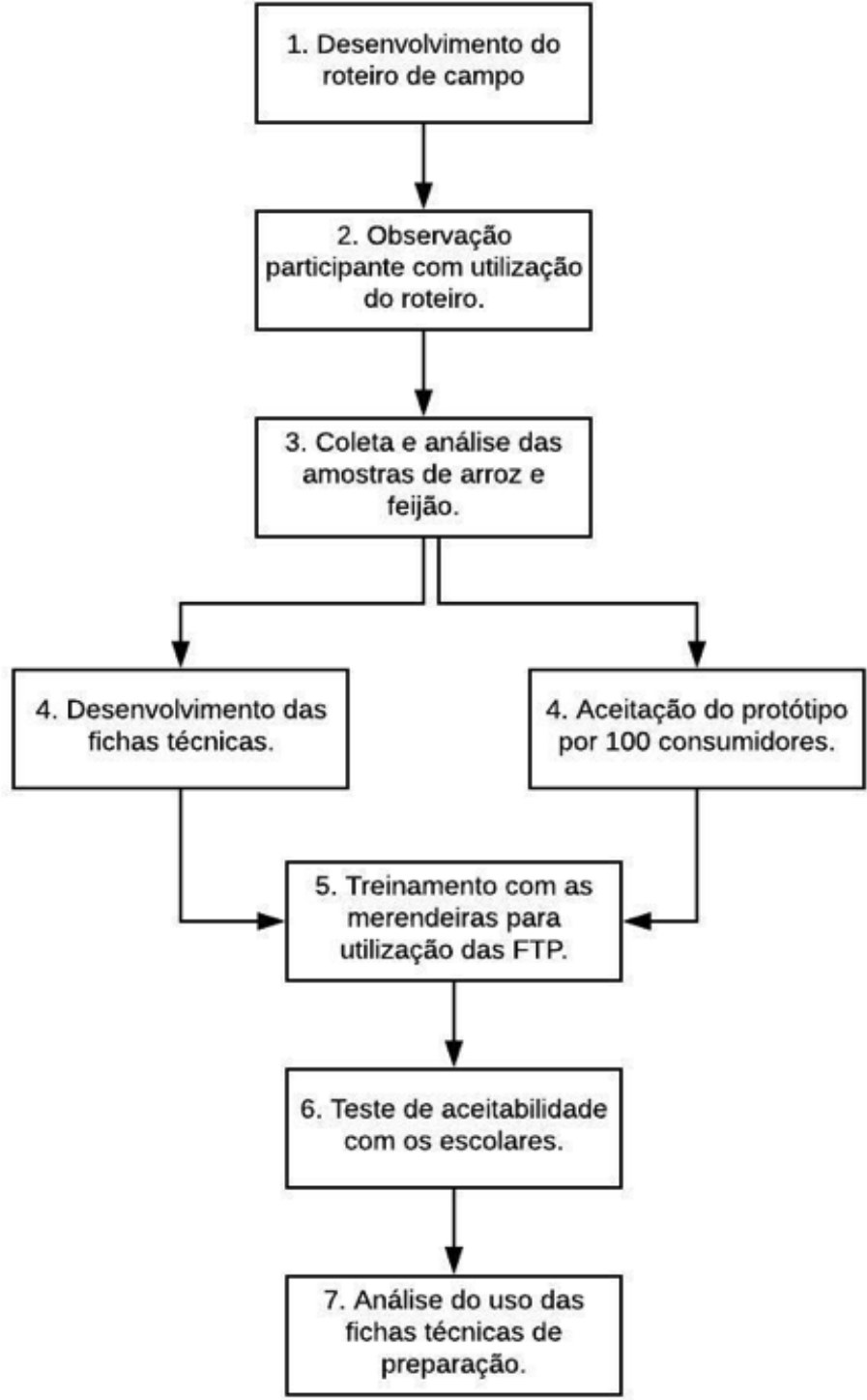

Fonte: Desenvolvido pelas autoras.

Inicialmente foi feita uma análise das preparações mais frequentes dos cardápios dos almoços planejados para escolas da mesma rede municipal de ensino, para o período de abril a julho de 2018, para posterior determinação das preparações que teriam FTPs produzidas. Os cardápios foram fornecidos pela direção da escola (ou coordenação de alimentação escolar do município estudado). A opção pelo arroz branco e feijão preto foi devido à frequência destas preparações ocorrer em todas as semanas do cardápio e na maioria dos dias. Ademais, estas duas preparações têm sua ingestão diária recomendada pelo Guia Alimentar para a População Brasileira, representando a cultura ali- 
mentar do país, além de possuir composição nutricional adequada em macro e micronutrientes. ${ }^{1,5}$

Com isso, desenvolveu-se um roteiro de campo a ser aplicado durante a observação participante por dois pesquisadores treinados, em dias não coincidentes e não consecutivos, totalizando quatro dias de observação. O roteiro contemplou os seguintes pontos: 1 ) uso de FTP; 2 ) técnicas utilizadas para a confecção das preparações escolhidas; 3 ) quantidade utilizada de sal (cloreto de sódio) e óleo vegetal de adição. Os dados coletados foram registrados em diário de campo.

Este método possibilitou a obtenção de todas as informações sobre a realidade e contexto da Uane na produção das preparações, como também os pontos críticos da adição de sal e óleo, além do registro dos fenômenos observados in loco na situação concreta em que aconteceram. ${ }^{6,7}$

A coleta das preparações arroz branco parboilizado e feijão preto foi realizada na própria Uane pelas pesquisadoras, em duplicata, com aproximadamente 100 gramas cada, em saco plástico do tipo zip bag específico para o armazenamento de alimentos, por quatro dias não consecutivos. ${ }^{8}$ As preparações foram armazenadas sob congelamento a $-80^{\circ} \mathrm{C}$ no Laboratório de Nutrição Experimental (Labne) da Faculdade de Nutrição Emília de Jesus Ferreiro (FNEJF) da Universidade Federal Fluminense (UFF) até o momento da análise.

As amostras de arroz e de feijão foram divididas em quadruplicadas com aproximadamente 5 gramas cada e levadas à estufa a 105으 por 3 horas em cápsulas de porcelana, e em seguida, resfriadas em dessecador até temperatura ambiente e pesadas em balança analítica. Esse procedimento foi feito até atingir um peso constante, obtendo então os resíduos secos das amostras. A determinação do teor de lipídios foi efetuada por extração direta em Soxhlet utilizando o apareIho de Soxhlet, seguida de aquecimento até o peso constante. ${ }^{9}$

O teor de sódio das preparações foi quantificado por meio da pesagem direta dos alimentos, seguindo as seguintes etapas: pesagem do sal utilizado pelas manipuladoras de alimentos com balança digital eletrônica com capacidade de até 10 quilogramas e precisão de 1 grama, marca FWB e modelo 91379; pesagem do utensílio para cocção das preparações e dos alimentos após sua produção. $\mathrm{O}$ cálculo de obtenção do sal na porção foi realizado pela fórmula: rendimento final da preparação = rendimento - peso do utensílio de cocção. ${ }^{10}$

No tocante à intervenção, utilizou-se o roteiro de observação que possibilitou obter as técnicas utilizadas para o preparo do arroz branco e feijão preto nas escolas para sua posterior análise e correlação com as características sensoriais e as técnicas observadas foram utilizadas na elaboração das FTPs. Utilizou-se o modelo da FTP recomendado no Manual de Apoio às Atividades Técnicas do Nutricionista no Âmbito do PNAE. ${ }^{11}$

No Laboratório de Alimentos e Dietética da FNEJF/UFF foi feito o preparo do arroz e feijão com adequação de sódio e lipídios levando-se em conta as etapas observadas na Uane. Para determinar essa adequação considerou-se a recomendação diária do PNAE para duas refeições, ou seja, até 600mg de sódio; 
11,3g de lipídios para a faixa etária de 6 a 10 anos e 16,3g para a faixa etária de 11 a 15 anos. $^{3}$

A recomendação do PNAE em relação às quantidades de sódio e lipídios não é específica para cada refeição e preparação que a compõe. Assim, o presente estudo dividiu a quantidade recomendada de cada nutriente por refeição e, posteriormente, pela quantidade de preparações nas grandes refeições do município (prato principal, dois acompanhamentos e uma guarnição). Com isso, as FTPs do arroz branco e feijão preto deveriam ter, no máximo, 75 miligramas de sódio e 2,03g de lipídio per capita considerando a faixa etária de 6 a 10 anos. ${ }^{12}$

A capacitação das manipuladoras de alimentos foi realizada durante 10 dias não consecutivos, utilizando a abordagem pedagógica comportamentalista. ${ }^{13}$ Nos 2 primeiros dias foram abordados conceitos teóricos sobre FTP, assim como a sua utilização e importância na melhora da qualidade sensorial e nutricional das preparações alimentares durante o processo produtivo de refeições.

No terceiro dia foram apresentadas as FTPs elaboradas e realizada a capacitação para o uso da quantidade de cloreto de sódio e do óleo em medida caseira. Para a realização da capacitação foram disponibilizados pelos pesquisadores os utensílios necessários (colher de chá e copo medidor de plástico), visto que a Uane não dispunha desses recursos, mas eram imprescindíveis para estabelecer as quantidades estabelecidas pela FTP. Posteriormente foi verificada a utilização das fichas técnicas desenvolvidas in loco pelas manipuladoras de alimentos com acompanhamento e auxílio do pesquisador em caso de dúvidas nos outros 7 dias.

A avaliação ocorreu mediante um estudo-piloto, em que foram recrutados estudantes de Graduação da área de saúde para avaliar a aceitação dos novos protótipos, de acordo com a disponibilidade, interesse e frequência de consumo de arroz branco e feijão preto maior que 4 (quatro) vezes por semana. Optou-se por testar primeiro o protótipo com adultos para que, caso houvesse necessidade, os ajustes seriam feitos antes da análise sensorial com o público-alvo final e para não saturar os escolares com os testes.

O teste de aceitabilidade foi realizado no Laboratório de Análise Sensorial da FNEJF/UFF, utilizando-se o teste de Escala Hedônica9, onde cada voluntário recebeu aproximadamente $30 \mathrm{~g}$ de cada amostra dos produtos em copos de plástico descartáveis codificados com números de três dígitos aleatórios, com temperatura controlada e utilizando um delineamento de blocos completos balanceados. Os atributos aceitação global, consistência, cor, aroma e sabor foram determinados utilizando para os julgamentos uma escala hedônica estruturada mista de 9 pontos, com as extremidades ancoradas nos termos "gostei muitíssimo" = 9, "desgostei muitíssimo" = 1 e "não gostei nem desgostei" = 5 no meio da escala.

Para o cálculo da aceitação utilizou-se a equação: IA= (Média de todas as respostas/5) x 100, sendo aceita a preparação com aceitação maior ou igual a $60 \%$ em todos os atributos.

Após a aprovação do protótipo, realizou-se o teste de aceitabilidade na Uane com escolares com idades entre 7 e 15 anos. A Escala Hedônica Facial mista de cinco pontos, adaptada para o público infantil, foi utilizada para o julgamento das preparações pelos escolares. Para o cálculo da aceitabilidade utilizou-se a 
equação descrita anteriormente, considerando-se o ponto máximo da escala (5 em escala de 5 pontos) como 100\%. Os resultados foram calculados da seguinte forma: percentual de Rejeição = soma dos percentuais das escalas detestei, não gostei e indiferente e percentual de aceitação = soma dos percentuais de gostei e gostei muito; sendo considerada aceita o percentual igual ou maior que $85 \% .{ }^{14}$

A observação participante com roteiro redigido para este novo momento, segundo Frantz et $a l^{6}$ e Hissanaga et $a l,{ }^{7}$ foi o método utilizado para a verificação do uso das FTPs propostas, avaliação dos pontos críticos e a certificação do controle de adição de sódio e de lipídios, respectivamente. Optou-se pelo uso desta metodologia para verificar o alcance dos objetivos da capacitação das manipuladoras de alimentos.

\section{RESULTADOS}

Com base no roteiro de campo, verificou-se que a FTP não é utilizada e a quantidade dos ingredientes utilizados no preparo das refeições fica a critério das manipuladoras de alimentos. Cabe destacar que a medida caseira utilizada para porcionar as preparações alimentares era a colher de sopa cheia, cuja gramatura variava entre elas.

Identificou-se como ponto crítico de controle a quantidade de sal adicionada nas preparações do arroz e feijão. Após o preparo, as manipuladoras de alimentos realizavam a degustação das preparações e verificavam o possível acréscimo de sal conforme gosto individual, sem qualquer padronização ou exatidão.

Um ponto observado foi o uso de óleo no tempero de alho, ou seja, o alho utilizado no arroz e feijão era triturado em grandes quantidades e adicionado óleo de soja para conservação sob refrigeração por um mês, observando-se que a proporção utilizada era de um litro de óleo para cada cinco quilos de alho. Não foi constatado o uso de produtos embutidos durante o preparo do feijão.

As FTPs postas em prática foram desenvolvidas respeitando as técnicas já empregadas pelas manipuladoras de alimentos (Tabela 1), visto que não interferiam na qualidade nutricional do arroz branco e feijão preto. Com relação ao óleo de adição foi mantida a quantidade habitual utilizada, por estarem em conformidade com a recomendação do PNAE.

Tabela 1 - Descrição das Técnicas de Preparo Utilizadas pelos Colaboradores

\begin{tabular}{c|c}
\hline \multirow{2}{*}{ Arroz } & $\begin{array}{c}\text { Lavagem dos grãos em água fria; } \\
\text { Feijão }\end{array}$ \\
\hline & $\begin{array}{r}\text { Água para cocção levada à fervura com o óleo e alho triturado; } \\
\text { Adição do arroz e sal com água em ponto de fervura; } \\
\text { Cocção até os grãos estarem cozidos. }\end{array}$ \\
& $\begin{array}{c}\text { Separação dos grãos; } \\
\text { Cocção dos grãos em água na panela de pressão; } \\
\text { Alho e cebola refogados em uma frigideira; } \\
\text { Adição do tempero após a cocção dos grãos; } \\
\text { Maceração dos grãos de feijão; }\end{array}$ \\
& Adição do sal e água até consistência mais líquida do caldo de feijão; \\
Cocção até ponto de fervura do feijão.
\end{tabular}

Fonte: Desenvolvida pelas autoras. 
O sódio foi reduzido a $34,5 \%$ da quantidade empregada antes da instituição da FTP, com o intuito de diminuí-lo até alcançar a quantidade definida na recomendação, sem interferir na palatabilidade. As Tabelas 2 e 3 representam as FTPs do arroz e feijão adotadas, respectivamente.

Tabela 2 - Ficha Técnica de Preparação do Arroz Branco

\begin{tabular}{|c|c|c|c|c|c|c|c|c|c|c|c|c|}
\hline \multicolumn{13}{|c|}{ FICHA TÉCNICA DE PREPARO } \\
\hline \multicolumn{13}{|c|}{ NOME DA PREPARAÇÃO: Arroz Branco } \\
\hline \multicolumn{3}{|c|}{ Ingredientes } & \multicolumn{3}{|c|}{ Peso Bruto(g) } & $\begin{array}{l}\text { Peso Líquido } \\
\text { (g) }\end{array}$ & \multicolumn{2}{|c|}{$\begin{array}{c}\text { Fator } \\
\text { Correção }\end{array}$} & \multicolumn{2}{|c|}{$\begin{array}{c}\text { Total peso/ } \\
\text { Volume }\end{array}$} & \multicolumn{2}{|c|}{$\begin{array}{l}\text { Custo } \\
\text { unitário }\end{array}$} \\
\hline \multicolumn{3}{|c|}{ Arroz branco polido } & \multicolumn{3}{|c|}{30} & 30 & & 1 & \multicolumn{2}{|c|}{$3 \mathrm{~kg}$} & & \\
\hline \multicolumn{3}{|c|}{ Óleo de soja } & \multicolumn{3}{|c|}{1,7} & 1,7 & & 1 & \multicolumn{2}{|c|}{$170 \mathrm{ml}$} & & \\
\hline \multicolumn{3}{|c|}{$\begin{array}{c}\text { Alho triturado+ óleo } \\
\text { de soja }\end{array}$} & \multicolumn{3}{|c|}{0,34} & 0,34 & \multicolumn{2}{|r|}{1,13} & \multicolumn{2}{|c|}{$34 \mathrm{~g}$} & & \\
\hline \multicolumn{3}{|c|}{ Sal refinado padrão } & \multicolumn{3}{|c|}{0,3} & 0,3 & & 1 & \multicolumn{2}{|c|}{$30 \mathrm{~g}$} & & \\
\hline \multicolumn{13}{|c|}{ COMPOSIÇÃO CENTESIMAL } \\
\hline & kcal & $\begin{array}{c}\mathrm{CHO} \\
\text { (g) }\end{array}$ & $\begin{array}{l}\text { PTNA } \\
\text { (g) }\end{array}$ & $\begin{array}{l}\text { LPD } \\
\text { (g) }\end{array}$ & $\begin{array}{l}\text { FIBRAS } \\
\text { (g) }\end{array}$ & $\begin{array}{l}\text { Vit A } \\
\text { (mcg) }\end{array}$ & $\begin{array}{l}\text { Vit C } \\
(\mathrm{mcg})\end{array}$ & $\begin{array}{c}\mathrm{Ca} \\
(\mathrm{mg})\end{array}$ & $\begin{array}{l}\mathrm{Fe} \\
(\mathrm{mg})\end{array}$ & $\begin{array}{l}\mathrm{Mg} \\
(\mathrm{mg})\end{array}$ & $\begin{array}{l}\mathrm{Zn} \\
(\mathrm{mg})\end{array}$ & $\begin{array}{l}\mathrm{Na} \\
(\mathrm{mg})\end{array}$ \\
\hline & 128 & 28,1 & 2,5 & 0,2 & 1,6 & 0 & 0 & 4 & 0 & 2 & 0,5 & 1 \\
\hline & 8,1 & 0 & 0 & 0,9 & 0 & 0 & 0 & 0 & 0 & 0 & 0 & 0 \\
\hline & 0,0 & 0,19 & 0 & 0 & 0 & 0 & 0 & 0 & 0 & 0,2 & 0 & 0 \\
\hline & 0 & 0 & 0 & 0 & 0 & 0 & 0 & 0 & 0 & 0 & 0 & 70,2 \\
\hline TOTAL & 137 & 28 & 2,5 & 1,1 & 1,6 & 0 & 0 & 4 & 0 & 2,2 & 0,5 & 71,2 \\
\hline
\end{tabular}

MODO DE PREPARO:

Retirar as sujidades e lavar o arroz em água corrente;

Em uma panela, colocar água, o óleo de soja e o tempero de alho triturado para ferver; Quando iniciar a fervura, despejar o arroz lavado, adicionar o sal e mexer; Deixe o arroz coccionar em fogo médio até que os grãos estejam cozidos; Sirva a preparação. 
Tabela 3 - Ficha Técnica de Preparação do Feijão Preto

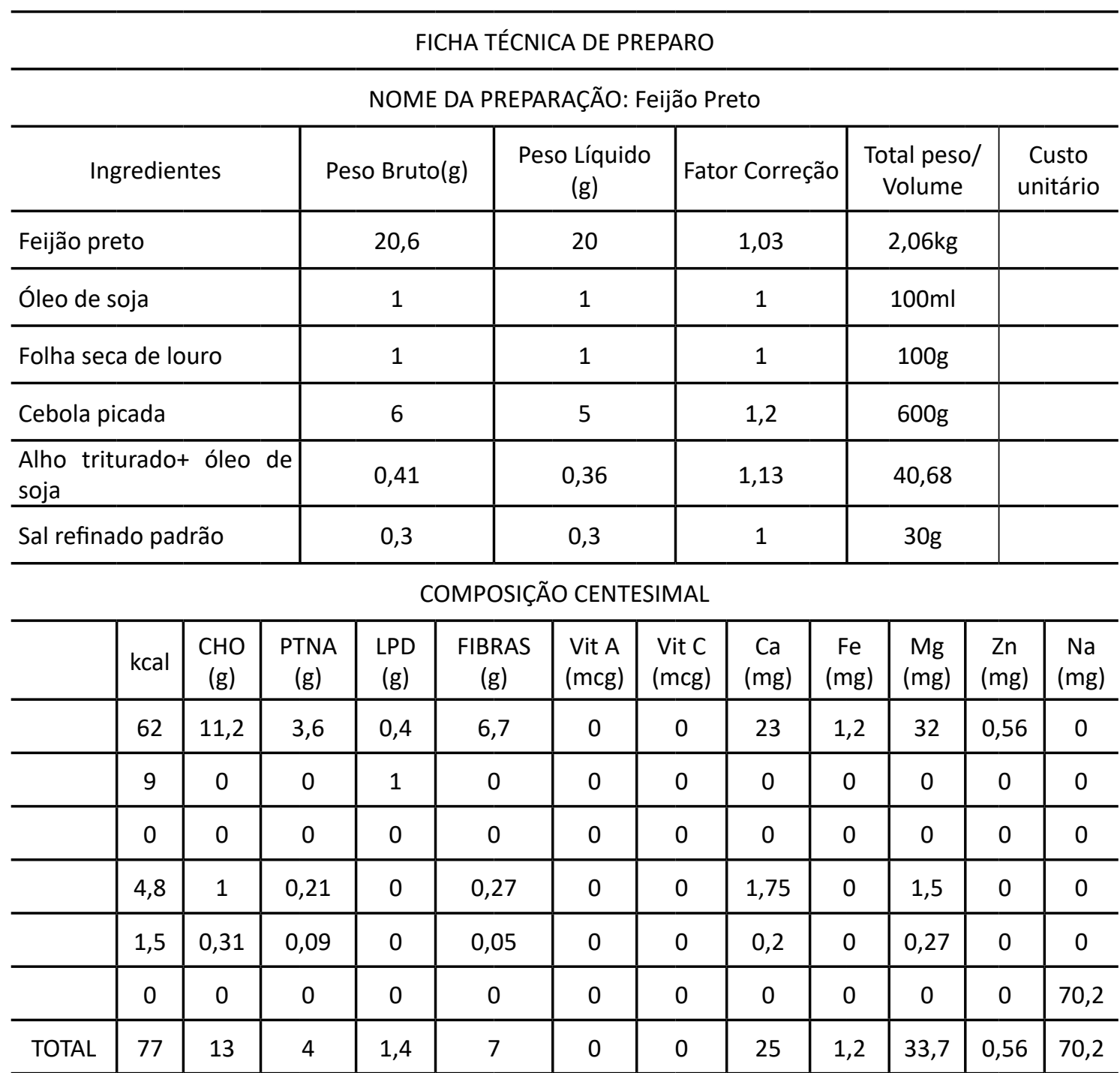

Porção: $80 \mathrm{~g}=1$ concha pequena

MODO DE PREPARO:

Selecione os grãos de feijão;

Em uma panela de pressão adicione água e o feijão;

Deixe coccionar até o feijão ficar cozido;

Em outra panela adicione o tempero de alho com óleo e refogue até dourar;

Adicione o feijão e caso haja necessidade, adicione um pouco de água;

Com um soquete de polietileno, macere os grãos;

Adicione o sal e deixe o feijão ferver por 30 minutos;

Sirva a preparação.

Fonte: Desenvolvida pelas autoras. 
Participaram da capacitação todas as manipuladoras de alimentos $(n=3)$ da Uane, quando elas realizaram a avaliação da mesma durante uma roda de conversa e elencaram como pontos positivos estarem no próprio local de trabalho, a metodologia utilizada e aprender sobre a redução do uso de óleo e sal de adição relatando que usariam isso em seus lares, cabendo pontuar que não houve referência a pontos negativos em relação à capacitação.

Em relação à participação da avaliação do protótipo das preparações, foram convidados cem estudantes de Graduação da área da saúde e revelou-se que os atributos preferidos do arroz branco e feijão preto foram a consistência (70\%) e o aspecto global (75\%). O que menos agradou foram o sabor do arroz branco (60\%) e a cor do feijão preto (65\%), com a aceitação final do arroz branco sendo de $65 \%$ e a do feijão de $72 \%$, caracterizando este protótipo como aprovado para ser utilizado na avaliação da aceitabilidade dos escolares.

O teste de aceitabilidade foi composto por 122 escolares do 1음 ao 5응 ano do Ensino Fundamental e o resultado demonstrou aceitabilidade das preparações após a introdução das FTPs, obtendo 86\% de aceitação para o arroz e 88\% para o feijão, segundo a soma das escalas gostei e adorei.

A Tabela 4 apresenta os resultados da análise centesimal das preparações arroz e feijão antes e depois da adoção da FTP, em que a quantidade do óleo de adição no arroz branco e feijão preto correspondia juntos a 1,83g antes da capacitação e adoção da FTP, não havendo necessidade de redução. Para padronizar foi necessário apenas defini-la quantitativamente por meio do copo medidor plástico com capacidade de $500 \mathrm{~mL}$ durante a capacitação dos colaboradores.

Tabela 4 - Resultados de extrato etéreo obtido nas análises centesimais do arroz e feijão

Extrato Etéreo: Quantidade em $100 \mathrm{~g}$ de amostra

\begin{tabular}{l|c|c|c|c|c}
\hline & $\begin{array}{c}\text { Arroz } \\
\text { Branco }(\mathrm{g})\end{array}$ & $\begin{array}{c}\text { Feijão } \\
\text { Preto }(\mathrm{g})\end{array}$ & Total $(\mathrm{g})$ & $\begin{array}{c}\text { Recomendação } \\
(6-10 \text { anos })\end{array}$ & $\begin{array}{c}\text { Recomendação } \\
(11-15 \text { anos })\end{array}$ \\
\hline Antes & 0,46 & 1,37 & 1,83 & 11,3 & 16,3 \\
\hline Depois & 0,41 & 1,27 & 1,68 & 11,3 & 16,3 \\
\hline
\end{tabular}

Fonte: Fonte: Desenvolvida pelas autoras.

O roteiro de observação aplicado após a instituição das FTPs permitiu verificar que a capacitação alcançou os objetivos, pois além do seu uso, a quantidade de sal e óleo de adição acrescidas às preparações alimentares estavam de acordo com as FTPs estabelecidas, sem haver ajuste e interferência tendo como parâmetro o paladar pessoal. Esses excertos ilustram esses apontamentos: "a gente já sabia como fazer, mas agora fica mais fácil de usar as mesmas quantidades" (MA1); "com esses talheres novos para medir o sal é melhor (MA2)" e "melhor não ter modificado o jeito que a gente já fazia, só ficou melhor (MA1)".

O ponto crítico do óleo foi considerado de fácil controle por haver somente um momento de adição deste ingrediente na preparação. Já em relação ao 
ponto crítico da quantidade de sal a ser adicionada precisou ser estabelecido e definido o uso de utensílios apropriados para esta etapa de preparo, permitindo assim a padronização das medidas caseiras e, consequentemente, da quantidade de adição de sal nas preparações.

\section{DISCUSSÃO}

O PNAE desde 2013 exige o uso da Fichas Técnicas de Preparação (FTP) como ferramenta importante para a produção de preparações alimentares saudáveis e adequadas. Em 2017 publicou o Manual de Apoio para as Atividades Técnicas do Nutricionista do Âmbito do Pnae, no qual valoriza a FTP como instrumento norteador no preparo das refeições e trouxe um modelo padrão "com itens mínimos e necessários" para o seu planejamento, com possibilidades de mudança de acordo com a realidade de trabalho local.,3,14

Além disso, elas asseguram o atendimento às necessidades nutricionais dos escolares e o controle da adição de ingredientes culinários importantes como sal, açúcar e óleos. Ademais, auxiliam na padronização das preparações durante o processo produtivo de refeições, reduzem os custos, identificam pontos críticos, o controle do tempo necessário para execução e asseguram maior controle higiênico sanitário. Ressalta-se que as FTPs ainda propiciam a uniformidade do aspecto sensorial, garantindo a aceitação constante das preparações. ${ }^{4,11}$

Não é, contudo, uma atribuição de fácil execução, visto que estudos apontam a sua ausência na Uane em alguns municípios, ${ }^{15,16}$ prejudicando a padronização das refeições. Provavelmente, caso a FTP fosse considerada um instrumento para boas práticas de fabricação, integrando o processo gerencial e de controle, esta seria amplamente utilizada.

Estudos que avaliaram as boas práticas em diversos pontos do Brasil, como nos Estados do Rio de Janeiro, ${ }^{17}$ Piauí, ${ }^{18}$ Rio Grande do Sul ${ }^{19}$ e Tocantins ${ }^{20}$ não mencionaram o uso da FTP em Uane. Visando a facilitar e agregar qualidade ao monitoramento do processo, Stedefeldt et al ${ }^{21}$ desenvolveram um instrumento para avaliar as boas práticas de fabricação voltado especificamente para unidades de alimentação nas escolas, no entanto não incluíram o uso da FTP como item obrigatório.

Ao identificar um percentual elevado de sódio fornecido pela preparação arroz branco e feijão preto acima do valor per capita determinado como referência, cabe salientar que o consumo de uma refeição completa é composta também pela guarnição e prato principal, destacando-se que essa recomendação inclui duas refeições, o que poderia representar, ao final do dia, que os estudantes estariam ingerindo uma quantidade de sódio acima do recomendado caso consumissem estas preparações todos os dias. Em contraponto, o percentual de lipídios encontrado antes e após a introdução da FTP estava de acordo com o recomendado pela legislação. ${ }^{3}$

Diante deste cenário, fica evidenciado que o uso de FTP é fundamental e que os manipuladores precisam ser qualificados para a sua instituição. As metodologias a serem utilizadas com esta finalidade devem perpassar pelos campos da aprendizagem, de modo a possibilitar que os manipuladores desenvolvam au-

Editora Unijuí - Revista Contexto \& Saúde - ISSN 2176-7114 - v. 21, n. 44, out./dez. 2021 
tonomia e a reflexão crítica sobre suas práticas laborais, pois como evidenciado na literatura, as mudanças de paradigma tendem a ocorrer quando se usa metodologias ativas, como oficina culinária, atividades lúdicas, dramatização, aulas dialógicas e elaboração de poemas, sempre ponderando previamente o levantamento de informações, estudo da realidade e o público-alvo para então, escolher a prática educativa mais adequada. ${ }^{22-24}$

A diminuição do teor de sódio não implicou a aceitabilidade do público infantil, corroborando outro estudo que apontou que, embora haja por parte deste ciclo de vida uma preferência por alimentos mais salgados, ao realizar a redução de sódio e utilizar técnicas que melhorem a palatabilidade do alimento é possível alcançar boa aceitabilidade..$^{25}$

Diferente desses resultados, o trabalho realizado por Silva Júnior ${ }^{26}$ testou a redução do sódio em uma preparação do prato principal substituindo o sal refinado padrão por um "sal de ervas" (alecrim, louro, manjericão, coentro, orégano e alho) para escolares, e o resultado do teste de aceitabilidade foi de $75 \%$, valor inferior aos $80 \%$ necessários para ser considerado como aceito e incluído no cardápio escolar.

Raros são os estudos no Brasil sobre esta temática, redução do sódio e lipídio na alimentação escolar com apresentação de novas preparações e seus respectivos testes de aceitabilidade e fichas técnicas. A necessidade de redução do teor de sódio é um problema internacional, observando-se que no Brasil existem diversas políticas públicas e processos tramitando no Congresso Nacional dando apontamentos da necessidade de haver redução destes, bem como suas implicações.

Por isso, a importância de atividades como as desenvolvidas neste estudo para promover ações educativas no tocante à alimentação saudável e adequada nas escolas, que priorizem os hábitos culturais locais, alimentos regionais e agreguem valor nutricional, com a redução nos teores de sódio e lipídios, sem interferir na palatabilidade e aceitabilidade dos comensais., ${ }^{3,14}$

Uma limitação deste projeto foi a sua realização somente em uma escola, no entanto acredita-se que ao escolher as preparações mais frequentes e culturalmente aceitas do cardápio, facilitará a introdução das FTPs em outras Uanes.

\section{CONCLUSÃO}

Este estudo de intervenção apresentou uma metodologia factível para a adoção da FTP em Uanes e consequente redução da quantidade de sódio e controle da quantidade de lipídios ofertados. Destaca-se que os manipuladores de alimentos são agentes promotores da alimentação adequada e saudável e alçá-los ao protagonismo nos processos de formação e adoção da fichas constituiu-se em estratégia determinante para o alcance dos objetivos propostos.

Desta forma, a instituição da FTP, além de ser uma prerrogativa explícita do PNAE, potencializa a promoção da saúde e da Educação Alimentar e Nutricional por meio da adoção de hábitos alimentares saudáveis. Por fim, sugere-se uma agenda de pesquisa nessa área para acompanhar o processo de utilização

Editora Unijuí - Revista Contexto \& Saúde - ISSN 2176-7114 - v. 21, n. 44, out./dez. 2021 
de fichas técnicas por um período mais longo com avaliações frequentes do impacto das mudanças acarretadas na padronização das preparações.

\section{REFERÊNCIAS}

${ }^{1}$ Monteiro LS, Rodrigues PRM, Sichieri R, Pereira RA. Intake of saturated fat, trans fat, and added sugars by the Brazilian population: an indicator to evaluate diet quality. Eur J Clin Nutr. 2020. [citado 29 set. 2021]. [Acesso em: 20 abr. 2020]; 74:1316-1324. Disponível em: https://doi.org/10.1038/s41430-020-0582-y

${ }^{2}$ Huang L., Trieu K., Yoshimura S., Neal B, Woodward M, Campbell NRC, Li Q, Lackland DL, Leung AA, Anderson CAM, MacGregor GA, He FJ. Effect of dose and duration of reduction in dietary sodium on blood pressure levels: systematic review and meta-analysis of randomised trials. BMJ [Internet]. 2020 [citado 29 set. 2021]. [Acesso em: 20 abr. 2020]; 368:m315. Disponível em: https://doi.org/10.1136/bmj.m315

${ }^{3}$ Brasil. Fundo Nacional de Desenvolvimento da Educação FNDE. Resolução no 6 de 8 de maio de 2020. Dispõe sobre o atendimento da alimentação escolar aos alunos da educação básica no âmbito do Programa Nacional de Alimentação Escolar - Pnae. 2020. [Acesso em: 20 abr. 2020]. DOU. Imprensa Nacional. Disponível em: in.gov.br

${ }^{4}$ Pereira IGS, Lemos LW, Lemos KGE, Almeida RDCC, Botelho RBA, Camargo EB. Construção e implementação de fichas técnicas de preparação de unidade de alimentação e nutrição. Journal Health NPEPS, 2019. [citado 29 set. 2021]; 4(1):210-227. [Acesso em: 20 abr. 2020]. Disponível em: https://periodicos.unemat.br/index.php/jhnpeps/article/ view/3388

${ }^{5}$ Brasil. Ministério da Saúde. 2014. Guia alimentar para a população brasileira. 2014. [Acesso em: 20 abr. 2020]. Disponível em: http://www.cfn.org.br/wp-content/uploads/2015/12/Guia-Alimentar-da-Populacao-Brasileira.pdf

${ }^{6}$ Frantz CB, Veiros MB, Proença RPC, Sousa AA. Development of a method for controlling salt and sodium use during meal preparation for food services. Rev Nutr [Internet]. 2013 jan. [citado 29 set. 2021]; 26(1):75-87. [Acesso em: 20 abr. 2020]. Disponível em: https://doi.org/10.1590/S1415-52732013000100008

${ }^{7}$ Hissanaga VM, Block JM, Proença RPC. Development of a method for controlling trans fatty acids in Meals-MCTM. J Culin Sci Technol [Internet]. 2012 mar. [citado 29 set. 2021]; 10(1):1-18. [Acesso em: 20 abr. 2020]. Disponível em: https://doi.org/10.1080/ 15428052.2012 .650601

${ }^{8}$ São Paulo (Estado). Secretaria de Saúde. Coordenação dos Institutos de Pesquisa. Centro de Vigilância Sanitária. Portaria CVS n. 5, de 9 de abril de 2013. (2013). Aprova o regulamento técnico sobre boas práticas para estabelecimentos comerciais de alimentos e para serviços de alimentação, e o roteiro de inspeção, anexo. 2013. [Acesso em: 20 abr. 2020]. Disponível em: http://www.cvs.saude.sp.gov.br/up/PORTARIA\%20 CVS-5 090413.pdf

9 Instituto Adolfo Lutz. Métodos físico-químicos para análise Alimentos. 2008. [Acesso em: 20 abr. 2020]. Disponível em: http://www.ial.sp.gov.br/resources/editorinplace/ ial/2016_3_19/analisedealimentosial_2008.pdf

${ }^{10}$ Barbosa RMS, Oliveira N, Ferreira D, Dias P, Pereira S, Soares D, Henriques P. Análise das quantidades de óleo e sal de adição em refeições escolares. Revista Contexto \& Saúde. 2020;20(38):138-144.

${ }^{11}$ Brasil. Ministério da Educação. Fundo Nacional de Desenvolvimento e Educação FNDE. 2018. Manual de apoio para as atividades técnicas do Nutricionista do Âmbito do Pnae. Disponível em: [https://www.fnde.gov.br/index.php/programas/pnae/pnae-area-gestores/pnae-manuais-cartilhas/item/10493-manual-de-apoio-para-as-atividades-técnicas-do-nutricionista-no-mbito-do-pnae]. Acesso em: 20 abril 2020.

${ }^{12}$ Dumas LLV. Aceitabilidade da redução de sódio em um restaurante de Taguatinga Norte. Brasília. [Trabalho de Conclusão de Curso de Especialização em Gastronomia e Saú- 
de] - Universidade de Brasília. 2008. [Acesso em: 20 abr. 2020]. Disponível em: http:// dx.doi.org/10.26512/2008.TCC.330

${ }^{13}$ Cortada S. Teorias e fundamentos da educação. São Paulo: Editora Senac; 2019.

${ }^{14}$ Brasil. Ministério da Educação. Fundo Nacional de Desenvolvimento e Educação - FNDE. Testes de Aceitabilidade no Programa Nacional de Alimentação Escolar (Pnae). 2017. [Acesso em: 20 abr. 2020]. Disponível em: https://webcache.googleusercontent.com/ search?q=cache:miz5e7_JBrYJ:https://www.fnde.gov.br/index.php/centrais-de-conteudos/publicacoes/category/110-alimentacao-e-nutricao\%3Fdownload\%3D5096:manual-para-aplicacao-dos-testes-de-aceitabilidade-no-pnae $\& c d=1 \&$ hl=pt-BR\&ct=clnk\&gl=br\&client=safari

${ }^{15}$ Barbosa RMS, Coutinho MBC, Mendonça D, Silva DB, Henriques P, Anastacio A, Pereira S. School nutrition program: Assessment of planning and nutritional recommendations of menus. Rev Chil Nutr. 2017;44(2):170-176.

${ }^{16}$ Souza CAND, Longo-Silva G, Menezes RCE, Araujo ADC, Toloni MHDA, Oliveira MADA. Adequação nutricional e desperdício de alimentos em Centros de Educação Infantil. Ciência \& Saúde Coletiva [Internet]. 2018 dez [citado 29 set. 2021]; 23:41774188. [Acesso em: 20 maio 2020]. Disponível em: https://doi.org/10.1590/1413812320182312.30742016

${ }^{17}$ Soares DSB, Henriques P, Ferreira DM, Dias PC, Pereira S, Barbosa RMS. Boas Práticas em Unidades de Alimentação e Nutrição Escolares de um município do Estado do Rio de Janeiro - Brasil. Ciência \& Saúde Coletiva [Internet]. 2018 dez. [citado 29 set. 2021]; 23:4077-4083. [Acesso em: 20 maio 2020]. Disponível em: https://doi. org/10.1590/1413-812320182312.23992016

${ }^{18}$ Mendes TIL, Monteiro MLS, Carvalho LMF, Bezerra KCB. Condições higiênicas e sanitárias de unidades de alimentação e nutrição de escolas em tempo integral. Revista Eletrônica Acervo Saúde. 2019 [citado 29 set. 2021]; (31):e1150-e115. [Acesso em: 20 abr. 2020]. Disponível em: https://doi.org/10.25248/reas.e1150.2019

${ }^{19}$ Fortes KSB, Brasil CB, Silva JP, Pontes BD, Graupe M. Condições higiênico-sanitárias de unidades de alimentação e nutrição de escolas de educação infantil de Palmeira das Missões - RS. Vigilância Sanitária em Debate: Sociedade, Ciência \& Tecnologia [Internet]. 2017 jul. [citado 29 de set. de 2021]; 5(3):37-43. [Acesso em: 20 abr. 2020 [Disponível em: https://doi.org/10.22239/2317-269x.00959

${ }^{20}$ Ferro LL, Fialho CJ, Pires CRF, Teles NB, Santos VF. Condições higiênico-sanitárias de Unidades de Alimentação e Nutrição de escolas públicas do Estado do Tocantins. Segurança Alimentar e Nutricional. 2018;25(2):118-130.

${ }^{21}$ Stedefeldt E, Cunha DT, Silva Júnior EA, Silva SM, Oliveira ABA. Instrumento de avaliação das Boas Práticas em Unidades de Alimentação e Nutrição Escolar: da concepção à validação. Ciência \& Saúde Coletiva [Internet]. 2013 abr. [citado 29 set. 2021]; 18(4):947-953. [Acesso em 24 maio 2020]. Disponível em: http://dx.doi.org/10.1590/ S1413-81232013000400006

${ }^{22}$ Sangioni LA, Cadore GC, Botton AS, Vogel FSF, Silva ERA, Smaniotto H, Ratzlaff FR, Vasconcellos JSP. Impactos do curso de boas práticas de manipulação de alimentos em estabelecimentos de serviços de alimentação de Santa Maria, Rio Grande do Sul. RVZ [Internet]. 2019 fev. [citado 29 set. 2021];26:1-8. Disponível em: https://rvz.emnuvens. com.br/rvz/article/view/163. [Acesso em: 4 maio 2020].

${ }^{23}$ Santos VF, Pires CRF. Estratégia de formação para manipuladores de alimentos de escolas públicas atendidas pelo Pnae. Revista Ciência em Extensão [Internet]. 2019. [citado 29 set. 2021]; 15(2):50-60. Acesso em: 4 maio 2020. Disponível em: https://ojs.unesp. br/index.php/revista_proex/article/view/1796

${ }^{24}$ Fonseca KZ, Pamponet JSS, Prazeres AGM. Lima CLB, Santos IP. Formação para manipuladores de alimentos: conhecimento sobre flavonoides e desenvolvimento de preparações para a alimentação escolar. ELO [Internet]. 2017 abr. [citado 29 set. 2021]; 6(1). [Acesso em: 4 maio 2020]. Disponível em: https://periodicos.ufv.br/elo/article/ view/1157 doi: https://doi.org/10.21284/elo.v6i1.213 
${ }^{25}$ Liem DG. Infant's and children's salt taste perception and liking: A review. Nutrients [Internet]. 2017. [citado 29 de setembro de 2021]; 9(9):1011. [Acesso em: 20 abr. 2020]. Disponível em: https://doi.org/10.3390/nu9091011

${ }^{26}$ Silva Júnior FV. Teste de aceitabilidade de um tempero à base de ervas em substituição ao uso do sal na merenda escolar de uma escola estadual no município de Gravatá-PE. 2019. [Acesso em: 20 fev. 2021]. Disponível em: https://repositori.ufpe/handle/123456789/29000

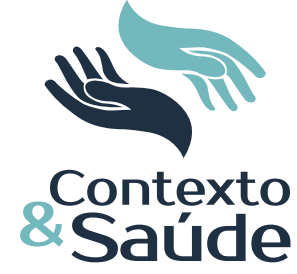

